\title{
A NEW NONLINEAR INTEGRAL INEQUALITY \\ OF WENDROFF TYPE WITH CONTINUOUS AND \\ WEAKLY SINGULAR KERNEL AND ITS APPLICATION
}

\author{
FAHIM LAKHAL
}

\begin{abstract}
The main objective of this paper is to establish some new explicit bounds for nonlinear integral inequalities of Wendroff type with continuous and weakly singular kernel, which generalized some known inequalities for functions in two variables and can be furnished a handy tool for the study of qualitative as well as quantitative properties of solutions of nonlinear differential equations. Some applications are also given to illustrate the usefulness of our results.
\end{abstract}

Mathematics subject classification (2010): 42B20, 26D07, 26D15.

Keywords and phrases: Wendroff inequalities, singular integral inequalities, nonlinear differential equations.

\section{REFERENCES}

[1] E. F. Beckenbach And R. Bellman, Inequalities, Ergebnisse der Mathematik und ihrer Grenzgebiete, Springer, Berlin, Germany, 1961.

[2] V. Lakshmikantham and S. Leela, Differential and Integral Inequalities: Theory and Applications. Vol. I: Ordinary Dfferential Equations, Mathematics in Science and Engineering, Academic Press, New York, NY, USA, 1969.

[3] D. BAĬNOV AND P. SimeOnov, Integral Inequalities and Applications, vol. 57 of Mathematics and Its Applications, Kluwer Academic Publishers, Dordrecht, The Netherlands, 1992.

[4] R. P. AgARwal, Difference Equations and Inequalities, Marcel Dekker, New York, NY, USA, 1993.

[5] B. G. PAChPATte, Inequalities for Differential and Integral Equations, vol. 197 of Mathematics in Science and Engineering, Academic Press, San Diego, Calif, USA, 1998.

[6] B. G. PAchpatTe, On generalizations of Bihari's inequality, Soochow Journal of Mathematics, Vol. 31, No. 2, pp. 261-271, April 2005.

[7] D. Henry, Geometric Theory of Semilinear Parabolic Equations, vol. 840 of Lecture Notes in Mathematics, Springer, Berlin, Germany, 1981.

[8] K. M. FURATI AND N. TATAR, Power-type estimates for a nonlinear fractional differential equation, Nonlinear Analysis: Theory, Methods \& Applications, vol. 62, no. 6, pp. 1025-1036, 2005.

[9] M. MEDVED, A new approach to an analysis of Henry type integral inequalities and their Bihari type versions, Journal of Mathematical Analysis and Applications, vol. 214, no. 2, pp. 349-366, 1997.

[10] M. Medved, Nonlinear singular integral inequalities for functions in two and $n$ independent variables, Journal of Inequalities and Applications, vol. 5, no. 3, pp. 287-308, 2000.

[11] M. MEdved, Integral inequalities and global solutions of semilinear evolution equations, Journal of Mathematical Analysis and Applications, vol. 267, no. 2, pp. 643-650, 2002.

[12] F. JiAng AND F. MENG, Explicit bounds on some new nonlinear integral inequalities with delay, Journal of Computational and Applied Mathematics, vol. 205, no. 1, pp. 479-486, 2007.

[13] Q.-H. MA AND J. PeČARIĆ, Some new explicit bounds for weakly singular integral inequalities with applications to fractional differential and integral equations, Journal of Mathematical Analysis and Applications, vol. 341, no. 2, pp. 894-905, 2008.

[14] W. S. Cheung, On some new integrodifferential inequalities of the Gronwall and Wendroff type, Journal of Mathematical Analysis and Applications, vol. 178, no. 2, pp. 438-449, 1993. 
[15] Q. H. MA AND E. H. YANG, Estimates on solutions of some weakly singular Volterra integral inequalities, Acta Mathematicae Applicatae Sinica, vol. 25, no. 3, pp. 505-515, 2002.

[16] A. P. Prudnikov, Yu. A. BRychkov, AND O. I. Marichev, Integrals and Series. Elementary Functions, vol. 1, Nauka, Moscow, Russia, 1981.

[17] W.-S. CHEUng, Q.-H. MA, AND S. TSENG, Some new nonlinear weakly singular integral inequalities of Wendroff type with applications, Journal of Inequalities and Applications, vol. 2008, Article ID 909156, 13 pages, 2008.

[18] H. WANG AND K. Zheng, Some Nonlinear Weakly Singular Integral Inequalities with Two Variables and Applications, Journal of Inequalities and Applications, vol. 2010, Article ID 345701, 12 pages, 2010. 